\title{
The Effects of Teachers' Training on Professional Development and Teaching Practice: A Case Study of Two Selected Colleges in Bangladesh
}

\author{
Mohammad Jahangir Hossain Mojumder (Ph.D.) ${ }^{*}$
}

\begin{abstract}
Nowadays, demands are growing for outcome-based and transferable learning, particularly in higher education. Being the terminal formal schooling, it needs facilitation of pupils' achievement of problem-solving skills for real-life by teachers. To this end, this qualitative research employs a case study approach, which is suitable to test an event with small samples, and a phenomenological method to analyze respondents' perceptions and activities thematically and descriptively to assess changes. In-depth interviews, focus group discussions, and class observations are used to collect data from two selected colleges to examine the extent of professional development and methodological shift in teaching as effects of training to include active learning strategies for better learning outcomes. The data though reveals that the selected flagship training program offers a bunch of pedagogical methods (not need-based) to imbibe, yet reject the idea that the nationally arranged training remains a successful effort to increase trainees' knowledge, skills, and polish attitudes except disseminating a few concepts superficially. Moreover, trainees lack the motivation to shift their teaching habits and are unconvinced that the application of these newly learned strategies will transform anything. Likewise, they are discontented about training contents and unenthusiastic in consort with unfavorable opinions about training procedures and trainers to some extent. Therefore, the results suggest limited or no significant professional development and modification in teaching practice, rather teachers continue conventional teacher-centered method, and the effort stays insufficient, extraneous, 'fragmented', and 'intellectually superficial'. Additionally, at the colleges, large class size, inappropriate sitting arrangement, pervasive traditionality, absenteeism, and other analogous challenges limited them to change their practice. Considering all these, this study suggests that alternations should be initiated at a micro (teachers \& college) and macro-level (training providers \& policymakers) to offer tailor-made, autonomous, and need-based training. Last but not the least, this endeavor is limited by being entirely qualitative with small sample size and not eliciting the views of any of the trainers and policymakers and which can be an indication of points of departure for future study.
\end{abstract}

Keywords: Bangladesh, Professional Development, Teacher, Leadership, Training

\section{Introduction}

Given that better learning outcomes of students stay as key targets of the teaching-learning process,-they require continuous meticulous demarches to ensure the achievements. In this

\footnotetext{
*Chowmuhani Government SA College, Bangladesh. Email: jahangirhm@gmail.com
} 
alignment, teachers need to be aware and familiarized with different customs of innovative and effective pedagogic and andragogic knowledge and skills to practice a wide range of teaching strategies and methods in and outside of classrooms depending on contexts (Ulla \& Winitkun, 2018). For this, teachers are provided with multidimensional job-implanted professional development (PD) opportunities (Wilson \& Berne, 1999), such as - formal and informal training, instructions related courses, participation in national and international conferences and workshops. By and large, expectations by pupils are to change teaching practices, develop educational institutions and accelerate the embodiment of higher-order skills of Bloom's Taxonomy (Borko, 2004; Mizell, 2010). Nonetheless, to be effective, the processes need to be continuous and adaptable, based on reflections of the programs and practices that followed (OECD, 2005).

Despite wider acceptability and being practiced globally, the obligation of prior training for the teaching profession is not mandated in Bangladesh (Raqib, 2019). That is, the government, in National Educational Policy-2010, categorically mentioned the appointment of skilled teachers and the proposition of training for further improvement (GoB, 2010). Here, though different types of arrangements for in-service PD are offered, yet diverse provisions of teachers' training are available at different levels (Chowdhury \& Sarkar, 2018). For instance, elementary school teachers go for one-year-long training at PTI (Primary Teachers' Training Institute) and then are offered regular other training and monthly cluster meetings at the sub-district level. Likewise, for secondary education, B.Ed. (Bachelor of Education), a one-year-long formal course is promoted, and other regular and donor-aided training are arranged (Karim \& Mohamed, 2019); however, the outcome regarding accruing of knowledge on contents remains insignificant (Asadullah, 2017). In this regard, the initiatives for teachers of about 2,272 colleges (National University, 2020) remain few, though high eminence in instructions by teachers at these colleges stands truncated (Raqib, 2019). Amongst these teachers, who belong to government colleges encounter a lack of initiatives for training or other types of PD, except mandatory four-month-long, nationally conducted, flagship program, Foundation Training Course (FTC), against the demands for incessant training. As a rule, these teachers are recruited first and then sent to selected colleges for classroom teaching without any pre-service orientation/training; and after serving for several years, they receive a call for joining FTC and the process bears the risk of being comfortable to traditional teaching methods by the beginners (Johannes, et al., 2013). At the 
regimented FTC, around 250 teachers, divided into three large groups, from all over Bangladesh, take part. However, the efficacy of this training program is scarcely explored. In this regard, Ali and Mawa (2019) did one, but that covered the foundation training only for university teachers.

Nevertheless, the training provider and government must reflect on the programs to identify the training outcomes, select skills to be entrenched, and set the methods of delivery. Therefore, understanding the insights and requirements of teachers and the relevance of the program to such demands stays crucial for the efficacy of the training in a resource-constrained country. These surely open the chances for redesigning the program and can engender critical discussions on the challenges teachers have been facing in classrooms and probable solutions to such obstacles. Moreover, the number of studies in Bangladesh on the effects of PD remains low, and found to reveal conflicting results with some positive and no visible outcomes. Thus, this study is believed to be worthy of merit and is going to offer insights regarding the compatibility of the program to teachers' PD and the degree of improvement in teaching. To explore the extent of relevance and effects of training, this study has selected FTC as the training to examine because, for many respondents, it is the only training opportunity in their service life.

Under the given background and stated problem, the objective of this research is to explore the effects of training for college teachers in Bangladesh, particularly, the effects of FTC on PD and shifts in teaching strategies at college-level education. In this alignment, this research endeavor has envisioned to set the specific objectives: (i) to investigate the teaching strategies provided by NAEM (National Academy for Educational Management) through FTC, (ii) to find out the magnitude of attainment of PD and implementation of the teaching strategies learned at FTC in their classrooms by teachers at the selected colleges, and (iii) to identify the weaknesses of FTC alongside the barriers teachers face while implementing learned teaching strategies at the respective colleges.

This research is not only significant to the context of Bangladesh, but also to other countries where the passion for 'didactic career' is dying intensely over the period, the teachers require to receive increased pedagogical training continuously and resourceful supports to work with aptitude and devotion to teach their students (Drăghicescu, et al., 2018). Similarly, the meaningfulness of such cannot be glossed over and need to be seriously explored. However, as studies remain scarce in Bangladesh, it is little known, whether or not FTC brings changes in 
teaching practice. Thus, this study is anticipated to add value to understand the perceptions of teachers regarding the relevance and effects of FTC for PD that translated into the inclusion of modern teaching strategies to didactical improvement. The results of this study are also expected to contribute to the growing knowledge on PD in Bangladesh by examining diverse modalities of FTC-related outcomes, teachers' perceptions, and reflections of FTC in their teaching practice. Likewise, the outcomes of the research - inputs, and insights - have implications for teachers, the authorities of colleges and NAEM, and policymakers to revisit and reform FTC, and the academia across the globe can be benefited from fresh results if pedagogical settings and frameworks are more or less similar in nature of implementation.

Theoretically, however, this research has not included the approaches of adult learning to explore the effects of training. Equally, methodologically, it has not relied much on quantification and statistical tools to gather and examine data, analyzed resources used for training, and elicited trainers' and policymakers' views and trainers' proficiency. Moreover, the numbers of colleges and respondents counted in the study are as low as suggested by Creswell (2013). Hence, these lacunas can be points of departure for further exploration on the issue. However, this study follows the qualitative method which is persistent in educational research, for example, Karim and Mohamed (2019) observed that the process though does not end in generalization yet stays prominent to deliver phenomenological insights of a training program. Moreover, being completely qualitative with a limited sample size, this research is not substantial enough to offer decisive suggestions. However, it is believed to suffice, through the application of methodological triangulation (Morse, 1991) and quantifying some qualitative data, to a satisfactory notch in warranting indicative recommendations for teachers of the government colleges to be reinforced with training to cope up with the needs of the digital era and the situation like Covid-19 pandemic.

\section{Literature Review}

\section{FTC - An Overview}

At FTC, both male and female teachers, most of the same age and salary scale, from government colleges of Bangladesh are trained once in a lifetime mandatorily under a common curriculum. These teachers are almost automatically chosen according to their age and batch at recruitment for civil service. At the beginning of a batch, comparatively older teachers are called first, if not 
for anything but to get their job permanent. Housed in the capital city - Dhaka, NAEM, the training provider is resourced with facilitators from mainly General Education Cadre Service, and partly from direct recruitment. However, these two sets of trainers are not enough, and thus, the institution regularly invites renowned professionals from other sectors. Additionally, the institute with various resource constraints bears the responsibility of training thousands of teachers and administrators from a plethora of colleges, secondary schools, and educational departments from regional and national levels. Thus, it becomes difficult to accomplish FTC for all new teachers timely. Nonetheless, FTC maintains homogeneity to a great extent with the curriculum of a similar type of training program organized by BPATC (Bangladesh Public Administration Training Centers) (NAEM, 2019). However, that does deny the dissimilar needs of professionals across services, predominantly of teachers.

In this government-paid four-month-long residential training, the participants of different disciplines are trained together on varied development, administrative, pedagogic, and andragogic theories and methods, and education-related issues based on a common curriculum without focusing on subject contents. In total, they must accomplish 22 modules and of which number 22 (education and related contemporary issues) is dedicated to the teaching-learning purposes. It includes training sessions of about 30-40 hours; the key topics related to this study are - educational issues and different pedagogic and andragogic concepts and strategies. During the course, the participants are evaluated through formative and summative assessments, offering 25 marks for each category (NAEM, 2019).

\section{Conceptual and Theoretical Framework}

The investigative literature on the learning processes of a teacher is relatively new. According to Borko (2004), evidence on teacher PD and its outcomes has been researched for nearly four decades. To this end, Desimone et al. (2002) stated that researchers are working very recently on identifying the contents and the process of learning by teachers and the links between PD and change in teaching and then on student learning outcomes.

Provided that teachers play key roles to augmented learning outcomes of understudies, Hawley and Rosenholtz (1984) confirm that amongst wide-ranging reasons that influence learning of students irrespective of their types - below average, average or above-average - teacher stands as the principal factor in every context. Thus, for a better student learning experience, teachers' 
PD remains imperative. For this, treating 'teaching' and 'teacher' as 'profession' and 'professional,' respectively carries value. Hence, the question stands - what does PD mean? Though in reality, PD means many things to many, Joyce and Showers (1988) relate this with an accumulation of knowledge on subject matter and skills in teaching-learning. In this line, Day (1999) extends a comprehensive definition, to him PD....

is the process by which, alone and with others, teachers review, renew and extend their commitment as change agents to the moral purposes of teaching; and by which they acquire and develop critically the knowledge, skills, and emotional intelligence essential to good professional thinking, planning, and practice with the children, young people and colleagues through each phase of their teaching lives (p. 4).

Apart from the aforementioned views, Borko, et al. (2010) emphasize the 'constructivist' and 'situative' approaches, instead of behavioral models; and thus, against, mandatory, common, and periodical traditional efforts for PD. According to Smylie (1995), teachers learn more from their colleagues at workstations, when they obtain control over the processes (Sykes, 1996). Moving forward, Garet et al. (2001) underline process and materials - collective and active participation of teachers, and focus on contents for effective PD. However, the success of this type of program depends on the relatively shorter length of the course (Kennedy, 1998), which is able to integrate teachers' experiences and offers prospects for receiving knowledge and skills with and from colleagues - but not from someone in authority (Sandholtz, 2002) - without separating from institutions (Lieberman, 1995).

Now, the question is - 'what is PD for'? In reply, Corrigan and Haberman (1990) argue that teachers must be professionally skilled enough to make use of four basic components of teaching - enhancing knowledge, ensuring quality, supporting with necessary resources, and congenial atmosphere - to intelligently deliver better teaching. Inspired by these, researchers, for example, Pezaro (n.d.) suggests that teachers need to focus on students' varied outcomes by modifying their teaching practices to be well conversant and smart. Thus, nowadays, according to Borko and Putnam (1995), the inclusion of sophisticated teaching strategies becomes necessary to impart intricate knowledge and skills, and the process needs to be included in school vision. However, academicians like Tang (2018) does not want teaching-learning to remain locked in four-wall of schools, rather include teachers' attainment of basic soft life-skills - 'teamwork', 
'communication', 'critical thinking' and 'problem-solving skill' - which are important for improved teaching and learning. For this, PD, according to OECD (1998), contributes to adapting, developing, and applying new teaching strategies of 'active learning'.

Here, PD is the key to assist the teacher in replacing conventional methods with active learning. Being important for bringing about changes - receiving a sense of the way forward, reinvigorating confidence, developing reflective and positive attitudes, motivating for employing critical stances, taking risks - PD needs varied types of intended efforts (Kohonen, 2001). Some notable efforts of PD are - pre-service and in-service training, various courses, reading related books and articles, participating in workshops, seminars, conferences, distant courses, engaging with professional groups, receiving foreign training, doing classroom-based action research, observing classroom activities, coaching or mentoring, and integrating technologies (Khan, 2008). Amongst these different measures of PD, in-service training stays important and wellpracticed.

Though teachers do not categorize in-service training as the most successful effort (Smylie, 1989), it has been yet treated as one of the key mechanisms for PD. Again, Smylie (1996) argued that against other mechanisms - education-related policies and projects for guiding tutor activities - for shifting classroom practice, in-service training stays as the most effective one. Because policymakers sometimes stay incompetent (Spillane \& Thompson, 1997) and in other cases, teachers disregard the modifications (Cohen \& Ball, 1990) at the policy level that planned to touch their classroom activities. However, the outcomes of such shifts can be 'additive' or 'transformative' through the proliferation of new knowledge and skills or fine-tuning of attitudes and practice respectively (Day, 1999).

What does the empirical evidence reveal? Supovitz et al. (2000) identify that if the training becomes concentrated, 'inquiry-based plus need-based (Sandholtz, 2002), then teaching practices to shift sustainably to include intended strategies. Likewise, Desimone et al. (2002) find evidence of change in instructions of teachers when professional learning stays active. Recent studies suggest that the application of modern technologies and methods for teachers' training brings noticeable changes in teaching practice (Gómez-Carrasco et al., 2020). From another point of view, a study in India presents that the efforts for PD resulted in building teachers' awareness to notice students' needs and development of conducive school atmosphere (Goel, 
2019). Likewise, in a study conducted on the secondary level in Bangladesh, Asadullah (2017) argues that those who receive training exhibit comparatively better teaching skills than those who do not. However, he discovers that in real-time teaching, teachers do not practice the learned strategies to the full extent. Similarly, Karim and Mohamed (2019) divulge that trainees learned a lot at the programs, but when it comes to implementation, the examples remain few.

Hence, the pertinent question is - 'what does PD need to be successful'? Kennedy (1998) moves ahead and suggests that PD develops teacher ability, and that translates into students' better achievement, but it needs to be 'intensive' and 'sustained.' Then again, Shields et al. (1998) also forward arguments in favor of concentration and length of PD as they influence the extent of change in teachers. Although, there stays a debate - whether PD needs to work for behavioral change or focus on enhancing familiarity with subject contents and student learning. Rebutting the arguments, Asadullah (2017), and Kennedy (1998) argue that training on behavior obtains little effect, rather training on the subject matter and student learning results in better outcomes. Additionally, suggestions are offered to work simultaneously on teachers' PD and institutional development as in isolation, efforts for improving both remain abortive (Fullan, 1991). Apparently, revealing the complexity, Van Driel \& Berry (2012) mention that PD is not a 'linear process', rather it depends on contexts, school cultures, teacher attitudes, and beliefs.

\section{Teaching Methods/Strategies}

Though teaching strategies encompass a set of actions - processes, methods, and techniques - a teacher uses while offering instructions, yet in this study, the terms methods and strategies have been used interchangeably. Teaching methods can be divided into two categories - teacher and student-centered (Teach.com, n.d.). In the teacher-centered model, the teacher remains the key figure and students stay as passive receivers of instructions, while assessment becomes a separate and end process (Tularam \& Machisella, 2018). Reversely, in the student-centered model, pupils stay in the center and learn by doing, while assessment is continuous and considered as learning processes (Freeman et al., 2014). Nowadays, for its effectiveness to achieve higher-order thinking skills of Bloom's Taxonomy, the student-centered method has been recognized as a modern method. This study, with an aim to explaining the effects on teaching strategies, focuses on teaching strategies through employing modern teaching. Asaolusam (n.d.) describes modern learning methods as: 
A learner-centered and activity-based teaching method is used to get learners fully involved. ... It is called a constructivist approach because it enables the learner to construct her/his knowledge and skills through active participation in the teachinglearning process. The teacher only acts as a guide, leading the learners to achieve the teaching objectives of the topics through the activities the learners are engaged in during classroom interactions.

The chalk-talk and teacher-centered methods, which promote rote learning and are used commonly by many teachers, have become dysfunctional to a great extent (Poirier, 2017). Moreover, the use of modern teaching methods has become important because of transformational change in knowledge and information on a global and national perspectives. These points of departure demand such people who with their creativity and criticality explore new knowledge horizons, identify missing links, and offer innovative concepts for development in the $21^{\text {st }}$ century. To reach this level, pupils are needed to be made knowledgeable and skillful to be creative, problem-solver, self-dependent, and employable for macro-level development through modern teaching methods (Harari, 2019). Features of modern teaching practices stay diverse, such as, student-centered, task-based, resource-based, interactive, integrative, collaborative, use of real-life examples, applicable for all students along with comprehensive assessment for learning (Asaolusam, n.d.), which bring 'constructivism' and 'active learning' in the center.

Though it has significant role in higher education, teacher-centered method is losing prominence rather, when learning outcomes are considered, for treating students as passive actors due partly to its inherent focus on teachers (Poirier, 2017). Reversely, active learning, a concept with high potentials, demanding engagement of learners is being promoted (Felder \& Brent, 2009). From the scholars who advocate this method, for examples, Chi \& Wylie (2014) indicate that the tool, instead of encouraging rote learning, necessitates learners' 'cognitive and meaningful engagement' with materials and resources and activation of three learning domains - affective, psychomotor and cognitive (Clark \& Mayer, 2008). In that case, students can be involved in varied activities - engagement, demonstration, presentation, memorization, or a mixture of activities. However, the determination of usage of a method and activities depends on the subject matter and nature of students and their way of learning (Westwood, 2008), and needed to be creative. 


\section{Teachers' PD in Bangladesh}

Though 'deficiency in teaching' has been identified as one of the key barriers for ensuring quality education (Asadullah, 2017); yet in Bangladesh, PD initiatives for teachers of varying levels, particularly for higher level, stays limited (Chowdhury \& Sarkar, 2018), because of huge numbers of teachers and scarce opportunity to provide training timely. According to BANBEIS (2018), in 2018, 1.22 million teachers were working at wide-ranging educational institutes, and the number of teacher training institutes remained only 216. Moreover, there was no evidence of learning communities, teacher leadership, learning experience sharing, coaching, and mentoring while in-service training stayed limited (Thornton, 2006). In this backdrop, the government in collaboration with development partners takes varied measures through different projects College Education Development Project (CEDP), Teaching Quality Improvement (TQI) in Secondary Education, Secondary Education Sector Investment Program (SESIP), plus Secondary Education Quality and Access Enhancement Project (SEQAEP) - for PD (Hamid \& Baldauf, 2008). In the majority of the cases, the topics for training under these programs are selected by authorities and conducted by outside experts. Moreover, PD efforts for teachers of secondary level remain good in numbers, comparing to that for higher-secondary and tertiary level teachers, particularly for teachers at government colleges. For many, FTC remains the solitary program in career, except ICT (Information Communication Technology) training for some. At the same time, Hoque et al. (2010) claimed that they identified positive effects of PD on institutional development. They reveal that the outcomes have been significant when the focus is less on 'individual action inquiry' and more on teamwork, classroom reflection, and in-service training. Equally, Sarma et al. (2013) revealed shifts in teaching practice upon participating in training. However, Ali and Mawa (2019) identified that FTC for university teachers though revealed positive outcomes yet failed to enhance knowledge and skills and shape attitudes of teachers due to lack of variation of trainers and offering training detached from workstations. Moreover, while implementing learned skills, teachers encountered resistance from senior teachers.

\section{Conceptual Framework}

Figure 1 below shows that teacher's PD can be observed through teachers' competence and overturning of teaching practices in classrooms, as it is expected that PD contributes to the 
adoption of modern teaching strategies - student-oriented methods - for students' better learning outcomes.

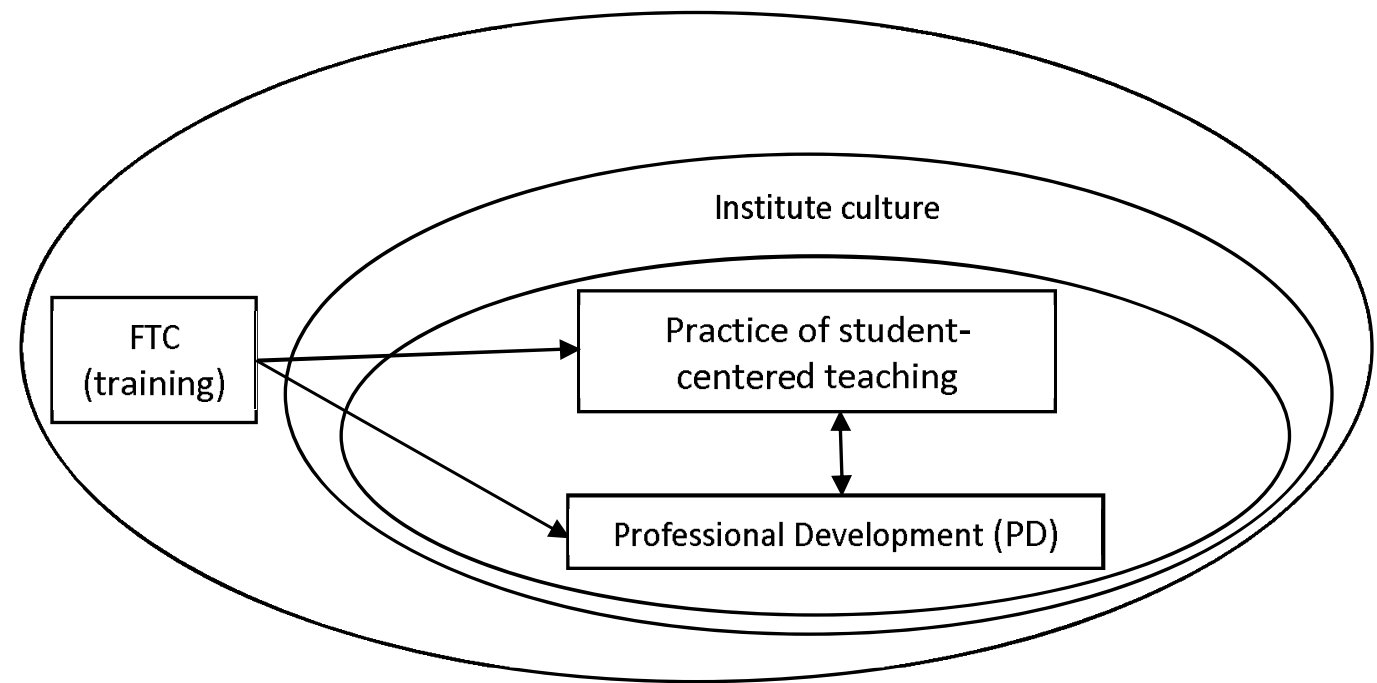

Figure 1: Theoretical Connection of PD and Teachers' Teaching Practice

Moreover, the processes of adoption of modern teaching strategies need to be supported by institutional culture and educational policy. Here, it is exhibited that nationally conducted FTC is a part of a state agenda and the study includes a single mode for PD training because of limited scopes and resource constraints. To identify the effects of FTC on teachers' professional competence and teaching practice, which can mutually influence each other; this study aims at examining teachers' teaching practice in the given context through analyzing methods of instructions and nature of activities and learning and perceptions of teachers.

\section{Implications of Literature Review}

The literature review illustrates that PD remains a complex process and consists of varied formal and informal methods. The principal target of PD is to enhance teacher knowledge and skills on contents of subjects, teaching-learning practice. It is also revealed that PD becomes effective when it is conducted based on needs and when teachers learn from their colleagues, rather than from persons in authority with direct instructions. Thus, efforts for PD isolating teachers from institutional settings stay a little operative. The review also confirms that the PD of teachers does 
not stand enough to bring transformation in teaching practice, as the process depends greatly on the institutional culture and national agenda. Thus, without changing school culture, efforts for PD to change teaching practice stay unsuccessful. The review concludes that between two methods of teaching - teacher and student-centered - the most desirable one is a student-centered style for its proven effectiveness to ensure better learning experiences for students. In this line, this study has mostly concentrated on examining the extent to which teachers practice studentcentered teaching-learning strategies in classrooms.

\section{Research Methodology}

The technique of the case study method, that is, a qualitative research design (Creswell, 2014) was employed for this study. The method, according to Yin (1984, p. 13), stays appropriate to test a phenomenon, program, event, individual, and/or other issues in its context and offers evidence, based on collected data from different sources. The method promotes in-depth analysis to obtain insights of the studied subjects and their relation when assimilating line of context and phenomenon becomes undetectable (ibid., p. 23). The analysis remained dependent on crosssectional data, which were collected from January to February 2020, a short and specified period to collect this type of data (Levin, 2006). This phenomenological approach steered scrutiny of perspectives of teachers and activities performed mostly in classrooms (Pringle, et al., 2011).

\section{Research Contexts}

Amongst two purposively selected government colleges, college-1 is at semi-urban sub-district level, college-2 is at the urban district level. The 77-year-old college-1 houses one two-storied building and two three-storied buildings of 21 classrooms for nearly 16,000 students (760 pupils per classroom) and 66 teachers (less than stipulated 96 posts). Likewise, college-2 has passed its centenary and houses 12 multi-storied buildings with about 150 classrooms for approximately 29,000 students (200 students per classroom) and 174 teachers (more than created 155 posts). However, encountering teacher shortage with high teacher-student ratio, both colleges offer higher secondary, undergraduate - degree pass, honors $(13 \& 18$ disciplines for college-1 \& college- 2 respectively) - and postgraduate ( $2 \& 18$ disciplines respectively) general courses of science, business studies, and humanities. Moreover, conventionally from the onset, these institutions have been experiencing teacher-centered learning, and chalk-talk stayed as the supreme tool. Likewise, the national policy dictates no formative assessment, so these 
institutions do not follow any till now. Though teachers learn best from their colleagues, there are no such pedagogical improvement efforts; for example, the presence of professional learning communities, the practice of teacher leadership, and other tailor-made college-based training except in-house ICT training.

\section{Sampling Process}

The participants of FTC, who received training within the last five years and presently working for the selected colleges, were the population.

Table 1: Samples of the Study

\begin{tabular}{|c|c|c|c|}
\hline Selected colleges & $\begin{array}{c}\text { Number of teachers } \\
\text { (who obtained training within last 5 years) }\end{array}$ & Samples & Percent \\
\hline College-1 (Sub-district level) & 12 & 8 & $67 \%$ \\
\hline College-2 (District level) & 18 & 12 & $67 \%$ \\
\hline Total & 30 & 20 & $67 \%$ \\
\hline
\end{tabular}

To select interviewees of both sexes, two government colleges from two different areas - semiurban and urban - were selected purposively for easy access, and from those institutions, eight (8) respondents from college-1 and 12 from college-2, i.e., the total of 20 were purposively selected to obtain relatively fresh experiences (Table 1 above). The small number of respondents conforms to Creswell's (2013) suggestion for the inclusion of four to five samples in a case study method.

\section{Data Collection}

Being small-scale, this study employed in-depth interviews, observation, and focus group discussions to elicit perceptions and insights. In each case study area, the interviews were conducted with the help of a schedule, which was developed based on the constructs derived from literature and was checked and piloted to make error-free. The interviews lasted for 40 to 45 minutes, and during progress, notes were taken and conversations were audio-recorded obtaining earlier permission. Moreover, two focus group discussion (FGD) sessions, one for each college, using a protocol, were organized by including five mid-level teachers, for each session, of both genders, other than interview respondents. During the discussion, notes were written and sessions were recorded. This tool assisted the researcher to crosscheck the interviewees' 
assertions and to explore further insights on the topic. Moreover, activities in four live classrooms have been observed to examine methodological practice by respondents. Notably, in every step of data collection, the researcher has maintained an ethical standards of research.

\section{Data Analysis}

The audio records of the interview, first, were transcribed and checked thoroughly to find and remove inconsistencies. Secondly, depending on varied key points, data were codified and used for thematic analyses. Similarly, FGD data were checked thoroughly and significant issues were codified to use for reinforcing descriptive in-depth analysis. Likewise, observational data and notes were used to illustrate narratives of the effects. In some cases, qualitative data were quantified for underpinning descriptive-analytical results. Moreover, obtaining the opinions, the recording was finalized in four categories - significant, moderate, little, and no change - to understand the achievement of PD.

\section{Reliability and Validity of the Processes}

The researcher offered, 'thick description' of the context, methods, and tools used for the research to warrant re-research. The interview schedule was developed based on the constructs derived from the literature. Before an interview, the respondents, chosen for obtaining valid data, were well-informed about the research topic and ways of data collection. Besides, the researcher obtained a trust-relationship with respondents as colleagues in a familiar context that warranted reliable data. To ensure creditability, the data, findings, and discussions were revisited by some respondents, and peers' comments were sought on the results to remove errors. Moreover, for validation of results, the researcher compared the outcomes with evidence from other studies.

\section{Findings and Discussions}

This section was prepared based mostly on the interview data and partly on FGD and observation data that sought teachers' experiences, perceptions, assessments, and knowledge of teaching strategies, FTC, and NAEM. The organization of this part developed descriptively on varied themes obtained from the three key questions provided in the introductory section and maintained the sequence of the questions. 


\section{Teaching Strategies Offered by NAEM}

The participating teachers were offered varied types of theoretical and practical knowledge and skills for PD on education and teaching by NAEM. Amongst them curriculum development and implementation, education policy and finance, tools and techniques of assessment, adult learning theories and effectiveness of training, developing a creative question, teaching methods, teaching-learning materials, classroom management, are prominent. Besides, other theoretical, practical knowledge and skills include innovation for teaching, inclusive education, teachers' professionalism, co-curricular activities, prospect of higher education, students' problems, time management, micro-teaching and simulation, modern learning theories, institutional role on socialization, quality education and plans (NAEM, 2019). Moreover, during training periods, the participants were expected to familiarize themselves with varied learner-centered teaching methods and tools used by facilitators. According to some of the key informants and participants of FGDs, the methods and tools included collaborative learning (peer review, pair and group work, and group presentation). Others informed that the micro-teaching, brainstorming, mind mapping, jigsaw, snowball, demonstration, inquiry-based instruction, debriefing (resolving participants queries), mentoring and coaching, integration of technologies, and varied methods of formative assessment were prominent.

\section{Perception of Teachers towards Instruction Methods}

Commonly, teachers hold the belief that these methods stay difficult to implement, and thus, they remain unenthusiastic.

\section{Seriousness of Trainess}

$$
\text { Very serious Moderately serious } \quad \text { Not serious }
$$

\section{Graph 1: Seriousness of Trainees during Training Sessions}

They assumed, as FGD data revealed, they were not conversant with the mechanisms of these methods; and even remained skeptical about the success of them. Furthermore, they indicated, 
they did not learn theories and methods to that extent to which they would be able to apply in classrooms by themselves because lack of seriousness emanated from rooted undesirable beliefs. While data showed only one of each five participants was very serious, one of each two trainees remained lackadaisical (Graph 1 above). Some mentioned during FGD sessions that they completed FTC as an obligatory task with low expectation.

\section{Implementation of Taught Teaching Strategies}

This section investigated the teaching practices the teachers were employed in their classrooms. This would allow everyone to understand the extent and nature of the effects of FTC on teaching practice.

\section{Practice of Teacher-Centered Methods}

Data revealed, teachers of the selected colleges dominantly follow teacher-centered methods and strategies, like lecturing, particularly, plain lecture, chalk-talk, and question-answer - ignoring or focusing little on varied processes of making lecturing attractive and engaging students in the process (Classroom observation, 2020). Respondents, during the interview, unanimously mentioned for managing a large number of students, teacher-centered strategies stayed appropriate. The issue of an increased number of learners was true in a sense, but it did not disclose the whole scenario; as at the beginning of a session students came in huge numbers, even classrooms failed to accommodate them all. However, after several months, the number of students declined dramatically from a few hundred to only 30-40 in both colleges (Context observation, 2020). Interestingly, gaining a reduced number of students and being habituated, teachers did not shift teacher-centered methods and exhibited averseness to practice participatory and student-centered active learning; hence no discernible effect of FTC was observed in both colleges.

\section{Engaging Student with Activities}

Table 2: Activities Facilitated in the Classrooms

\begin{tabular}{|c|c|c|}
\hline Activities & Frequencies & Percent \\
\hline Quizzes & 20 & $100 \%$ \\
\hline Questions/Answers & 20 & $100 \%$ \\
\hline
\end{tabular}


Mojumder, M. J. H., The Effects of Teachers' Training on Professional Development ...

\begin{tabular}{|c|c|c|}
\hline Formal assessment for learning & 0 & $0.0 \%$ \\
\hline Debriefs & 6 & $30 \%$ \\
\hline PowerPoint presentation & 9 & $45 \%$ \\
\hline
\end{tabular}

Student-engaging activities in classrooms remain few in both colleges (Table 2 above). The common activities students performed were responding to teachers' questions and making inquiries (very few). Moreover, the assessment of students for learning remained low or almost absent. For informal formative assessment, according to classroom observation, all teachers, though not regularly, asked varied quizzes to the whole class, and interview data revealed that some teachers declared about written class-test, but on the exam day the number of students reduced to one-quarter of the regular. Two respondents confirmed assigning homework (accomplished by very few) and measuring development, and one of them credited FTC's microteaching. The other further added that all the internal exams for summative assessment, uncounted for the formal results, conducted untrustworthily, and remained unreliable. Therefore, extending instructions based on this type of assessment stayed defective. Some $30 \%$ of teachers, according to interview and classroom observation, allowed students to raise questions before finishing classes, but very few did so, and what had been asked was debriefed.

Data revealed that most of the student-engaging activities remained absent. Teachers were, as FGD participants disclosed, hindered by challenges emanated from varied corners, institutional culture, and lack of obligation to practice participatory activities. All respondents unusually blamed large class-size (100-200 students) for limited participatory performance. They told that it stood impossible for a teacher to apply many of the engaging strategies in such classrooms. Thus, they frequently brimmed students with traditional lectures. However, FGD data revealed, when the number of students reduced after a few months of the beginning of sessions, teachers did not increase student engagement for lack of true intention and goodwill, and skills. More than one-third of respondents disclosed that they had never tried to implement any of the teaching strategies learned at FTC due to, generally, lack of true intention. One respondent disclosed his belief while interviewing, "if we want, we can implement student-centered methods. Here, teachers lack the integrity to implement. In demo class (during training period), we performed varied teaching strategies quite well, but after returning to workstation we gave up all." 
The respondents' interview data revealed that many of the students remained incapable of accomplishing their activities given in the classrooms expectedly and believed that engaging in activities stayed waste of time. At sub-district level college, comparatively poor graders got admitted failing at renowned colleges; however, at the district level, the scenario remained unchanged. Respondents also blamed traditional classroom design for not offering engagement activities. They, in FGD sessions, mentioned - in classrooms, it remained difficult to form groups and pairs with immovable long tables and to move students to different parts of the classrooms. Additionally, they believed there was a lack of an amicable environment with frequent noises from loitering students outside to practice quality teaching in these colleges, as authorities failed to establish a congenial environment for effective teaching.

Another issue, the respondents brought forward was student absenteeism and the erratic nature of presence. Most respondents disclosed that students came to college at their will, and there was no pattern of their coming. Many times, they identified that those who came that day might come another day with a gap of several days. All these plunged them, as told in interviews, into confusion and frustration to maintain continuity of their teaching contents and methods. They added, each day they needed a new beginning and became upset with students' little learning and became discouraged to be involved seriously with teaching-learning.

The use of technology, according to interview data, stood limited and infrequent. While at college- 1 only one respondent mentioned using multimedia and PowerPoint, at college-2, two out of three respondents did the same, but irregularly. Direct observation revealed the same and identified that only three classrooms were equipped with multimedia systems, but two of them remained dysfunctional at college-1. In this regard, college-2 was more developed in its infrastructure.

Moreover, the length of a session for each class hour remained 45 minutes mostly. Respondents, in FGD sessions, mentioned that this short period caused difficulty to practice varied methods of student-centered teaching strategies. Additionally, usually, no classes were held after lunch break at both colleges. Therefore, the working hour became limited and thus, effective and efficient teaching with the presence of students stayed difficult. 


\section{Attainment of Professional Development}

Having been a flagship in-service training (Khan, 2008), FTC is in a position to modify behavior, knowledge on the subject matter, emotional intelligence, instruction methods. It also enhances the commitment for a better learning experience of learners through increased collaboration, networking, critical thinking and problem solving, planning, and practicing with both pupils and colleagues as results of PD.

Table 3: The Extent of PD as an Outcome of FTC

\begin{tabular}{|c|c|c|c|}
\hline Indicators & Levels of change & Frequencies & Percent \\
\hline \multirow{4}{*}{$\begin{array}{l}\text { Change in pedagogic and andragogic knowledge } \\
\text { level }\end{array}$} & Significant change & 0 & $0.0 \%$ \\
\hline & Moderate change & 10 & $50 \%$ \\
\hline & Little change & 8 & $40 \%$ \\
\hline & No change & 2 & $10 \%$ \\
\hline \multirow[t]{4}{*}{ Change in skills } & Significant change & 0 & $0.0 \%$ \\
\hline & Moderate change & 6 & $30 \%$ \\
\hline & Little change & 8 & $40 \%$ \\
\hline & No change & 6 & $30 \%$ \\
\hline \multirow[t]{4}{*}{ Change in attitudes } & Significant change & 0 & $0.0 \%$ \\
\hline & Moderate change & 3 & $15 \%$ \\
\hline & Little change & 10 & $50 \%$ \\
\hline & No change & 7 & $35 \%$ \\
\hline \multirow{4}{*}{$\begin{array}{l}\text { Change in teaching practice to include student- } \\
\text { centered teaching methods }\end{array}$} & Significant change & 0 & $0.0 \%$ \\
\hline & Moderate change & 2 & $10 \%$ \\
\hline & Little change & 2 & $10 \%$ \\
\hline & No change & 16 & $80 \%$ \\
\hline Change in ability on subject contents & No change & 20 & $100 \%$ \\
\hline \multirow{2}{*}{$\begin{array}{l}\text { Change in thinking, planning, practicing with } \\
\text { students and colleagues }\end{array}$} & Significant change & 0 & $0.0 \%$ \\
\hline & Moderate change & 2 & $10 \%$ \\
\hline
\end{tabular}




\begin{tabular}{|l|l|l|l|}
\hline \multirow{4}{*}{ Change in students learning } & Little change & 3 & $15 \%$ \\
\cline { 2 - 4 } & No change & 16 & $75 \%$ \\
\hline & Significant change & 0 & $0.0 \%$ \\
\cline { 2 - 4 } & Moderate change & 4 & $20 \%$ \\
\cline { 2 - 4 } & Little change & 4 & $20 \%$ \\
\cline { 2 - 4 } & No change & 12 & $60 \%$ \\
\hline
\end{tabular}

Against these expectations, however, Table 3 above displays rather a gloomy scenario, as quantification of qualitative data reveals there has not been much change in the given areas. While knowledge on pedagogy and andragogy has not much improved, the skills for implementing active learning methods were limited, and every four out of five respondents acknowledged 'no change' in teaching practice. However, during the interview, some respondents mentioned that they have exercised some of the methods at NAEM and if they become serious, they can conduct student-centered classes. In reality, they require a changed attitude; however, half of the respondents indicated no change in this respect. Moreover, increased knowledge on the subject matter can be an indicator of PD; contrarily, subject contents usually are not part of FTC, so no change is observed in this regard. Likewise, integration of colleagues and students for thinking, planning, and practicing is important to improve learning outcomes. In this regard, every three out of four respondents confessed that they did not perform much though initially after returning from training they had enthusiasm gradually it dispersed. Consequently, the majority of the respondents (60\%) specified 'no change' in students' learning experiences in both colleges. In short, corroborating Karim and Mohamed (2019), the study revealed limited or no application of learned (though limited) methods in classrooms. In essence, a remarkably limited level of PD was achieved as outcomes of FTC.

\section{Challenges in Achieving PD and Implementing Projected Teaching Strategies}

The findings indicated a gloomy picture of the effects of FTC on teaching practice. The questions remained - why did such melancholy outcomes are achieved from such a big-budgettraining program? The following issues, which are discussed elaborately following Table 4, offered the answers to this question. 
Table 4: Challenges of Applying Learned Student-Centered Teaching Methods

$>$ Absence of instruction for, a few examples of, and seniors' resistance for, implementing student-centered methods at the college level (85\%)

$>$ Absence of local level coaching and mentoring after joining (75\%)

$>$ Absence of pre-service training (100\%)

$>$ Absenteeism $(80 \%)$

> Habituated with teaching styles of respondents' own teachers \& colleagues $(80 \%)$

$>$ High teacher-student ratio $(100 \%)$

$>$ Inappropriate curricula and syllabi for the teaching profession (70\%)

> Lack of dedication to apply new methods (40\%)

$>$ Lack of informal connectivity with trainers and trainees (80\%)

$>$ Lack of skilled trainers $(50 \%)$

$>$ Little learning at FTC (50\%)

$>$ Long routine disciplined training $(25 \%)$

$>$ Unenthusiastic attitude towards training (65\%)

Unfavorable institutional infrastructure, sitting arrangement \& culture (85\%)

\section{Teachers' Low Level of Learning at NAEM}

Having been in teaching for several years, for many, FTC stood as the first formal opportunity for learning about educational instructions and related concepts. Half of the respondents declared they learned new methods at FTC (Table 4 above). One respondent, during the interview, mentioned, "Before going to NAEM, I have not heard the concepts - 'pedagogy' and 'andragogy.' I knew nothing about teaching methods and the learning process of students." That means the program has the potentials to offer the understanding of teaching-learning related concepts, issues, and strategies. Though trainees became oriented, data revealed that teachers had not become conversant on teaching strategies and did not share any imparted concepts with colleagues after their return. While mentioning the names of the strategies, they faltered and could not pronounce many. According to one of the key informants:

I have forgotten (many of them) what those were. We were taught varied teaching methods and strategies at NAEM. You know, the trainers also employed different types of 
teaching approach, such as - group and pair work, poster presentation, question-answer between groups. ... but ... the teaching-learning was cursory and not in-depth.

Now a question - why has this truncated knowledge? Firstly, the curriculum of the program, though for teachers, yet was not exhaustive for the teaching profession. Only one comprehensive module of the program was designated for education-related issues, as the respondents found the program is a mixture of varied types of administrative and development-related issues dominantly and teaching contents partly. One respondent shed light on the issues during the interview and mentioned, "As teachers, our FTC must be teaching-oriented, but it includes many issues unrelated with our profession. (Thus,) it becomes burdensome and unexciting and doesn't feel attached."

Secondly, no participants obtained any pre-service training (Table 4 above), and most of them participated in FTC after two to three years of teaching practice. Thirdly, these teachers were not offered any mentoring or coaching at the institution after joining as mentioned by two-thirds of the respondents. Therefore, they developed their own ways of teaching methods derived from learning by doing, which confirmed the continuation of customary teaching methods they experienced as learners previously (Seidel \& Hoppert, 2011, cited in Johannes, et al., 2013). Fourthly, in training sessions, according to interview data, they mostly exhibited reluctant attitudes and a lack of seriousness towards learning and adopting new strategies. Fifthly, a dichotomy in characteristics as member of cadre service and teaching professionals - several participants hesitated to be teachers unreservedly. One interviewee said, "Through cadre service we are officers and by profession we are teachers - actually we are not any of them to the full extent." Therefore, with this gulf in feelings, achieving FTC targeted knowledge and skills remained elusive and unaccomplished to a great extent.

Along this line, one out of two respondents exposed that they learned nothing special from FTC and no change was observed in teaching practice. One of them argued that he participated to confirm his job, as FTC stayed mandatory. Another one revealed he learned few techniques but never tried in classrooms. Additionally, during the interview, he added "we received some allowance, and they received some remuneration," which was another face of the training. The findings of the study suggest that the FTC failed to secure teachers' PD. Very few respondents recognized the notable professional change in them which made them knowledgeable and skilled 
to employ modern teaching strategies but did not translate into actions. Consequently, teachers continued practicing traditional methods and tried to defend their stance.

\section{Negative Feelings towards FTC}

The perceptions of majority respondents (65\%) towards NAEM and its training program, FTC, displayed inconsequentiality (Table 4 above). One respondent revealed that NAEM and its training seemed quite beneficial for the teachers of secondary level. As mentioned in the interview, according to him, for college teachers, the training program was not appropriate, and methods and contents would not fit them, and finally, the methods would make their students confused.

Similarly, FTC is branded by quarter of respondents as a disciplined routine task to be completed, and the intention of being benefitted professionally did not manifest during interviews (Table 4 above). They thought, in Bangladesh, people possess inherited escaping attitudes. During the interview, one respondent revealed:

We just sat as stones, heard, and forgot. (We) stored nothing in our notebooks or our head, and when came back to the workstation we did not bring anything. ... Our engagement in different activities during training sessions remained low and many of us displayed reluctant attitudes to participate in group activities and when got the chance evaded responsibility.

Two-fifth of respondents (Table 4 above) believed that these methods were not applicable and did not want to implement in their class, as they noticed low morality of the students and use of unfair means for completing their assigned tasks. According to one of the informants, "It won't be effective. I do not want to implement it. If we want, we can, but I think there is no scope to implement these at the college level." Equally, 65\% of participants mentioned that what they lacked most was true intention to learn from FTC and to implement in classrooms. In this line, as revealed by FGD and interview data, it is learned from $85 \%$ of respondents that colleges remained indifferent; neither promoted nor hindered, regarding implementation of new teaching strategies, except resistive attitudes from some seniors, and perceived that if college showed eagerness and offered a congenial environment, these could be implemented. 


\section{Mismatched Contents}

The contents of FTC at NAEM were matched with the same of other cadre services. Only one module has been developed for education-related concepts without inquiries and considering the needs of teachers. Thus, according to seven out of 10 respondents, PD intended for improving teachers' teaching quality with the inclusion of varied teaching strategies and methods for effective instructions and solving students' problems remained unfocused (Table 4 above). The common module was prepared for all irrespective of disciplines though extensive with issues except subject contents; however, trainers failed to cover all of them efficiently for the time constraints. One respondent, during the interview, recalled, "the module ... erred... did not attract as much. ... The number of sessions for teaching remained limited. The teaching methods remained inadequate. We expected more, but the program stayed packed with contents that did not match much with our profession." Such situations, marked by irrelevance and incompatibility of training contents for professional needs, as opined by Drăghicescu et al. (2018), can distract the focus of the trainees. However, one respondent, in his interview, wished that if they had to maintain similarity at FTC with the training of other services then there should be a separate specialized training focusing on teaching.

\section{Inept Trainers and Failure of Opportunities}

The respondents disclosed that half of the trainers were not quite competent to facilitate them (Table 4 above). A few of them, as exhibited, according to FGD data, conducted sessions without being prepared well; and thus, the trainees became irritated and lost interest. The responses of a respondent in the interview can be summarized, "some of the faculties with visible weaknesses failed to show their true capacity to train us. Moreover, their performance revealed that they did not make their preparation well, and these made their presentations weedy and nonchalant. Additionally, sessions remained non-participative to a great extent and adopted few theoretical paradigms and andragogic techniques; thus, participants got unenthusiastic, terming the sessions monotonous." However, comparatively, they liked some of the regular faculties and the lectures of guest speakers who were invited from various other institutions.

Then again, some trainers did not follow the strategies and methods they taught at FTC. Therefore, to trainees, it seemed to be insincerity and demotivated them to apply these in their classrooms. Some trainers were inexpert, inexperienced, and unenthusiastic, as they were not 
placed scrupulously at the training institute by judging their expertise. One respondent termed the institute as a workstation for privileged sections; and added that some of them were not equipped enough to train others, and just managing their routines cursorily.

Lieberman (1995) argues that training can be successful if it is conducted by and with colleagues mostly informally at working institutions because success is relatively low from formal authoritative training centers (Sandholtz, 2002). Accordingly, though the participants were trained by their senior colleagues, yet they failed to bring expected outcomes. While interviewing, four out of five respondents mentioned that they were not engaged informally with trainers, for instance, the dining tables, playgrounds, etc. (Table 4 above). On the other hand, it stays tough to be informal with so many participants. Moreover, a quarter of the respondents indicated that incessant training for a long time produced tediousness, rather short training courses around the year would yield better results. Then again, the trainees were almost of the same age group and the same grade of pay scale; that means, they formed a homogenous group, in which trainees are supposed to learn well (Desimone et al., 2002). Moreover, FTC remains as a residential course for quite a long period that offers ample time to concentrate on the course contents; however, these did not make expected results except an extension of networks.

\section{Improper Institutional Settings}

Back in colleges, both institutions failed, according to $85 \%$ of responses from interview data (Table 4 above), to provide required scopes for practicing student-centered teaching strategies. Thus, the interests of respondents waned gradually, and they started to believe that these western methods were not applicable here. The colleges tended to admit students beyond their capacity; therefore, there remained a high teacher-student ratio, and lack of resources made it degenerated as echoed by Ulla and Winitkun (2018). According to $85 \%$ of respondents, the culture of the colleges was not favorable to promote and practice student-centered methods. One respondent, during the interview, included, "I stuck to traditional methods. ... Nothing has been changed notably (after FTC). Like my predecessors, I also continue the traditional methods." To her, there goes the idea that "no change will occur; it will move as it was. Whatever is done students will not come regularly."

Accordingly, four out of five respondents termed absenteeism as curse. In another end, the respondents mentioned, during FGD sessions and interviews that they never thought of 
innovative ideas to tackle the problems; just looked for the weaknesses and discussed them negatively. However, returnees suggested for introduction of reward and multidimensional penalty systems for them based on continuous teaching evaluation by students and monitoring of principal instead of one annual summative assessment by the confidential report.

\section{Conclusion, Implications and Suggestions}

\section{Conclusion}

While demands are growing for outcome-based and transferable learning, particularly at higher education, as being the terminal formal schooling, the educational system needs to be capable of preparing students for real-life contexts and problems. This study searching for effects of FTC on PD and teaching practice of teachers at two selected government colleges explores several significant outcomes. In Bangladesh, for teachers at government colleges, initiatives for PD remain few and FTC is an important one of them. To assess the effects of FTC, a case study was used, and data were collected through interviews, FGDs, and observations. Considering all aspects, it has been learned that FTC offers a bunch of learner-centered and participatory teaching strategies to be implemented at colleges. However, the data reject the idea that the compulsory FTC remains a successful effort to increase knowledge, skills, and polish attitudes like the findings of Ali and Mawa (2019), and Sykes (1996). Hence, the results suggest, corroborating the findings of Karim and Mohamed (2019), with limited or no observable shift in teaching to apply theoretical approaches and active learning techniques in the study area. Thus, the effort stays insufficient, irrelevant, 'meaningless', 'fragmented' and 'intellectually superficial' substantiating the findings of Ball \& Cohen (1999). Here, the important issues amplified participation, spaced autonomy, refined skills for manipulating diverse learning styles, augmented commitment for embodying learning, and increased theoretical underpinning - for a training to be successful, are missing (Gómez-Carrasco, 2020). Therefore, FTC returnees, though trained mostly by their senior colleagues, continue the traditional teacher-centered methods, mostly 'chalk-talk' inertly in classrooms with a high teacher-student ratio, unpredictable absenteeism, and teachers' low skills for applying new strategies, though they believe they can practice if there is willingness. Likewise, their dispirited belief goes that nothing will change with shifts in teaching and classroom activities. 
The results deliver that 'no shift in teaching' at both colleges, having difference only in infrastructure, has commenced with low learning from FTC with the presence of negative perceptions. Validating the findings of Miller (1998), the results suggest that teachers do not hold positive attitudes towards this regimented program and find it uninteresting, unconnected, and monotonous. Similarly, some trainers remain amateurish and exhibit weakness and low-quality performance, and interestingly, do not practice strategies they proliferate. Moreover, the common curriculum and contents for all, accompanied by the absence of subject knowledge, do not fulfill the needs of all participants; and thus, FTC stays unattractive. As adult learners, trainees show interest in useful and applicable issues, so, at FTC, isolating from their institutions, teachers sit 'silent as stones' and become insensible finding the contents irrelevant (Glathorn, 1990). Lastly, the trainees remain skeptical about the implementation and success of the taught strategies in their classrooms as they are not supported by institutional culture with inappropriate class size and classroom design, incapable students, lack of instructional leadership, and supervision.

\section{Implications and Suggestions}

As this study reveals, FTC fails to yield to ignite changes in teaching practice and the process of PD stays a long-term procedure, which demands a great deal of passionate actions and active supports from all corners; and without such assistance, the process stays susceptible to produce negative results (Kohonen, 2001). Accordingly, in Bangladesh, many of these conditions remain unfulfilled. Thus, the study offers the following four sets of underlying suggestions.

Firstly, teachers should be inspired for the development of self-professionalism with enhanced knowledge, skills, and assimilation of technologies to lead the institution academically with innovation by seeking high-performance, short time, tailor-made training on expressed needs and from workable professional learning bodies.

Secondly, colleges need to develop a vision and integrate stakeholders in the planning and implementation process; particularly, teachers should be bestowed with transformative leadership aligned with responsibilities (Fullan, 1991). As teachers learn best at institutional setting formally and/or informally with and from colleagues, the college should arrange comprehensive and continuous programs - teacher leadership, team-teaching, research group, learning communities, in-house training, workshop, and seminar - for PD to develop an enabling 
ambiance for innovative student-centered teaching practice. The principal and senior colleagues should offer regular instruction/coaching/mentoring, necessary resources, and manageable students, and increase the performance evaluation process.

Thirdly, NAEM necessitates to redesign its curriculum and contents, and to develop a new model of training for more in-depth and focused PD assessing the needs of the trainees and following successful models of densely populated countries. Moreover, efforts should be made to appoint competent trainers through rigorous selection procedures and to build the capacity of existing facilitators. More can be done through visiting renowned institutions, increasing frequencies of short-term training, and decentralizing facilities to the grassroot level.

Finally, policymakers should focus on incessant, short, and trainee-centered training to fulfill the necessities of participants. Moreover, curricula and syllabi of subjects at colleges should be redesigned to enable student-centered methods, and instructions should be given to institutions to begin practicing modern teaching strategies and locally expand self-directed and autonomous efforts for PD. Besides, teacher recruitment policy should be changed to offer increased amenities to those who received pre-service training and/or degree on education.

\section{Acknowledgement}

The researcher would like to duly acknowledge College Education Development Project (CEDP), Ministry of Education, Government of the People's Republic of Bangladesh, the University of Nottingham Malaysia, and Dr. Rajeevnath Ramnath, Associate Professor at CAPE, UNMC for their supports in conducting this study.

\section{References}

Ali, M. M., \& Mawa, B. (2019). Impact of 'Foundation training for university teachers' conducted by Bangladesh Agricultural University. Bangladesh Journal of Extension Education 31(1\&2): 1-12.

Asadullah, S. (2017). Teaching practices and teacher education: Evidence from secondary schools of Dhaka, Bangladesh. Global Journal of Human-Social Science: $(G)$ Linguistics \& Education 17(1): 69-82.

Asaolusam. (n.d.). Modern teaching method. Retrieved from https://asaolusam.wordpress.com/2016/09/03/modern-teaching-method/ on January 20, 2020.

Ball, D. L., \& Cohen, D. K. (1999). Developing practice, developing practitioners: Toward a practice-based theory of professional education. In L. Darling-Hammond and G. Sykes (Eds.), Teaching as the learning profession, pp.3-31. San Francisco, CA: Jossey-Bass.

BANBEIS. (2018). Retrieved from http://data.banbeis.gov.bd/ on December 19, 2019. 
Borko, H. (2004). Professional development and teacher learning. Educational Researcher 33(8): $3-15$.

Borko, H., \& Putnam, R.T. (1995). Expanding a teacher's knowledge base: A cognitive psychological perspective on professional development. In T.R. Guskey and M. Huberman (eds), Professional development in education: New paradigms and practices, pp. 35-65. New York: Teachers College Press.

Borko, H., Jacobs, J., \& Koellner, K. (2010). Contemporary approaches to teacher professional development. International Encyclopedia of Education 7(2): 548-556.

Chi, M. T., \& Wylie, R. (2014). The ICAP framework: Linking cognitive engagement to active learning outcomes. Educational Psychologist 49(4): 219-243.

Chowdhury, R., \& Sarkar, M. (2018). Education in Bangladesh: Changing contexts and emerging realities. In Chowdhury et al. (eds.), Engaging in educational research: Revisiting policy and practice in Bangladesh, pp. 1-18. Singapore: Springer Nature.

Clark, R. C., \& Mayer, R. E. (2008). Learning by viewing versus learning by doing: Evidencebased guidelines for principled learning environments. Performance Improvement 47:513.

Cohen, D. K., \& Ball, D. L. (1990). Policy and practice: An overview. Educational Evaluation and Policy Analysis 12(3): 233-239.

Corrigan, D., \& Haberman, M. (1990). The context of teacher education. In Houston, W., M. Haberman and J. Sikula (eds.), Handbook of research on teacher education: A project of the association of teacher educator, pp.195-211. New York and London: Macmillan.

Creswell, J. W. (2013). Qualitative inquiry and research design: Choosing among five approaches $\left(3^{\text {rd }}\right.$ ed.). Thousand Oaks, CA: Sage.

Creswell, J. W. (2014). Research design: Qualitative, quantitative and mixed methods approaches $\left(4^{\text {th }}\right.$ ed.). Thousand Oaks, CA: Sage.

Day, C. (1999). Continuing professional development. London: Falmer Press.

Desimone, L. M., Porter, A. C., Garet, M. S., Yoon, K. S., \& Birman, B. F. (2002). Effects of professional development on teachers' instruction: Results from a three-year longitudinal study. Educational Evaluation and Policy Analysis 24 (2): 81-112.

Drăghicescu, L. M., Petrescu, A. M. A., Stăncescu, I., \& Gorghiu, L. M. (2018). The relevance of continuous training programmes dedicated for teachers from pre-university education. Revista Romaneasca Pentru Educatie Multidimensionala, 10(3): 6-16.

Felder, R. M., \& Brent, R. (2009). Active learning: An introduction. ASQ Higher Education Brief 2(4): 1-5.

Freeman, S., Eddy, S. L., McDonough, M., Smith, M. K., Okoroafor, N., Jordt, H., \& Wenderoth, M. P. (2014). Active learning increases student performance in science, engineering, and mathematics. Proceedings of the National Academy of Sciences 111(23): 8410-8415.

Fullan, M. G. (1991). The new meaning of educational change. New York: Teachers College Press.

Garet, M., Porter, A., Desimone, L. Birman, B., \& Yoon, K. (2001). What makes professional development effective? Analysis of a national sample of teachers. American Education Research Journal 38(4): 915-945.

Glathorn, A. (1990). Supervisory leadership: An introduction to instructional supervision. Glenview, IL: Scott Foresman.

GoB. (2010). National education policy. Dhaka: Ministry of Education. 
Goel, C. (2019). Improving professional practices of in-service teachers in Delhi. IOJET 6(3): 432-441.

Gómez-Carrasco, C. J., Monteagudo-Fernández, J., Moreno-Vera, J. R., \& Sainz-Gómez, M. (2020). Evaluation of a gamification and flipped-classroom program used in teacher training: Perception of learning and outcome. PloS one 15(7): 1-19.

Hamid, M. O., \& Baldauf, R. B. (2008). Will CLT bail out the bogged down ELT in Bangladesh?. English Today 24(3): 16-24.

Harari, Y. N. (2019). 21 Lessons for the 21st Century. London: Jonathan Cape.

Hawley, W.D., \& Rosenholtz, S. (1984). Good schools: A synthesis of research on how schools influence student achievement. Peabody Journal of Education 4(1): 1-178.

Hoque, K. E., Alam, G. M., \& Abdullah, A. G. K. (2010). Impact of teachers' professional development on school improvement - an analysis at Bangladesh standpoint. Asia Pacific Education Review 12(3): 337-348.

Johannes, C., Fendler, J., \& Seidel, T. (2013). Teachers' perceptions of the learning environment and their knowledge base in a training program for novice university teachers. International Journal for Academic Development 18(2): 152-165.

Joyce, B., \& Showers, B. (1988). Information processing: Models of teaching. Apots CA: Booksend Laboratories.

Karim, A., \& Mohamed, A. R. (2019). Examining the impact of an English in action training program on secondary-school English teachers' classroom practice in Bangladesh. The Qualitative Report 24(3): 441-469.

Kennedy, M. (1998). Form and substance in in-service teacher education. Madison, WI: National Institute for Science Education.

Khan, R. (2008). Developing professionally. The Dhaka University Journal of Linguistics 1(2): 169-180.

Kohonen, V. (2001). From isolation to interdependence in ELT: Supporting teacher development through a school-university partnership. In Edge, J (ed.), Continuing professional development: Some of our perspectives, pp. 40-49. London: IATEFL publications.

Levin, K. A. (2006). Study design III: Cross-sectional studies. Evidence-based dentistry 7(1): 2425.

Lieberman, A. (1995). Practices that support teacher development: Transforming conceptions of professional learning. Phi Delta Kappan 76(8): 591-596.

Miller, E. (1998). The old model of staff development survives in a world where everything else has changed. Harvard education letter focus series no. 11: 2-4.

Mizell, H. (2010). Why professional development matters. Retrieved from https://learningforward.org/wp-content/uploads/2017/08/professional-developmentmatters.pdf on February 18, 2020.

Morse, J. M. (1991). Approaches to qualitative-quantitative methodological triangulation. Nursing Research 40(2): 120-123.

NAEM. (2019). Training brochure. Dhaka: NAEM.

National University. (2020). College details. Retrieved from http://www.nubd.info/college/college_details.php on September 25, 2020.

OECD. (1998). Lifelong learning to maintain employability. Paris: OECD.

OECD. (2005). Teachers matter: Attracting, developing, and retaining effective teachers. Education and Training Policy. Paris: OECD. 
Pezaro, C. (n.d.). The role of a teacher and the purpose of education: How can evidence inform classroom practice? Retrieved from https://npjscilearncommunity.nature.com /users/19567-charlotte-pezaro/posts/13089-the-role-of-a-teacher-and-the-purpose-ofeducation on January 20, 2020).

Poirier, T. I. (2017). Is lecturing obsolete? Advocating for high value transformative lecturing. American Journal of Pharmaceutical Education 81(5): 1-2.

Pringle, J., Hendry, C., \& McLafferty, E. (2011). Phenomenological approaches: Challenges and choices. Nurse Researcher 18(2): 7-18.

Raqib, A. A. (2019). Innovations in Teacher Training at Higher Education in Bangladesh. Social Science Review 36(1): 221-231.

Sandholtz, J. H. (2002). Inservice training or professional development: Contrasting opportunities in a school/university partnership. Teaching and Teacher Education 18(7): 815-830.

Sarma, H., Islam, M. A., \& Gazi, R. (2013). Impact of training of teachers on their ability, skills, and confidence to teach HIV/AIDS in classroom: A qualitative assessment. BMC Public Health 13(1): 1-9.

Seidel, T., \& Hoppert, A. (2011). Merkmale von Lehrean der Hochschule [Characteristics of teaching at the university]. Unterrichtswissenschaft 39(2): 154-172.

Shields, P. M., Marsh, J. A., \& Adelman, N. E. (1998). Evaluation of NSF's State-wide Systemic Initiatives (SSI) Program: The SSIs' impacts on classroom practice. Menlo Park, CA: SRI.

Smylie, M. A. (1995). Teacher learning in the workplace: Implications for school reform. In T. R. Guskey, \& M. Huberman (Eds.), Professional development in education: New paradigms and practices, pp. 92-113. New York: Teachers College Press.

Smylie, M.A. (1989). Teachers' views of the effectiveness of sources of learning to teach. The Elementary School Journal 89(5): 543-558.

Smylie, M.A. (1996). From bureaucratic control to building human capital: The importance of teacher learning in education reform. Educational Researcher 25(9): 9-11.

Spillane, J. P., \& Thompson, C. L. (1997). Reconstructing conceptions of local capacity: The local education agency's capacity for ambitious instructional reform. Educational Evaluation and Policy Analysis: 19(2): 185-203.

Supovitz, J. A., Mayer, D. P., \& Kahle, J. B. (2000). Promoting inquiry-based instructional practice: The longitudinal impact of professional development in the context of systemic reform. Educational Policy 14(3): 331-356.

Sykes, G. (1996). Reform of and as professional development. Phi Delta Kappan 77(7): 465467.

Tang, K. N. (2018). The importance of soft skills acquisition by teachers in higher education institutions. Kasetsart Journal of Social Sciences 30: 1-6.

Teach.com. (n.d). Teaching methods. Retrieved from Teach.com on January 20, 2020.

Thornton, H. (2006). Teachers talking: The role of collaboration in secondary schools in Bangladesh. Compare: A Journal of Comparative and International Education 36(2): 181-196.

Tularam, G. A., \& Machisella, P. (2018). Traditional vs non-traditional teaching and learning strategies--the case of e-learning!. International Journal for Mathematics Teaching \& Learning 19(1): 129-158. 
Ulla, M. B., \& Winitkun, D. (2018). In-service teacher training program in Thailand: Teachers' beliefs, needs, and challenges. Pertanika Journal of Social Sciences \& Humanities 26(3): 1579-1594.

Van Driel, J. H., \& Berry, A. (2012). Teacher professional development focusing on pedagogical content knowledge. Educational Researcher 41(1): 26-28.

Westwood, P. (2008). What teachers need to know about teaching methods. Australia: Victoria ACER Press.

Wilson, S. M., \& Berne, J. (1999). Teacher learning and the acquisition of professional knowledge: An examination of research on contemporary professional development. In A. Iran-Nejad and P. D. Pearson (Eds.), Review of Research in Education 24: 173-209.

Yin, R. K. (1984). Case study research: Design and methods. London: Sage Publication. 